\title{
Green Synthesis of Silver Nano-Particles using Different Plant Leaf Extract for Nagpur Mandarin Coating - An Eco-Friendly Approach
}

\author{
S. D. Deshmukh", S. R. Patil and A. M. Sonkamble \\ Department of Horticulture, Dr. Panjabrao Deshmukh Krishi Vidyapeeth, Akola (MS), India \\ *Corresponding author
}

\section{A B S T R A C T}

\begin{tabular}{|l|}
\hline Ke y w o r d s \\
Nagpur mandarin, \\
Silver \\
nanoparticles, \\
Shelf life, \\
Spectrophotometer, \\
Leaf extract \\
\hline Article Info \\
\hline $\begin{array}{l}\text { Accepted: } \\
\text { 18 May } 2020 \\
\text { Available Online: } \\
\text { 10 June } 2020\end{array}$ \\
\hline
\end{tabular}

Ecofriendly synthesis of nanoparticles is new, safe, speedy and emerging trend in field of nano-technology. The present study conducted at Post Harvest Technology laboratory, Department of Horticulture, Dr. Panjabrao Deshmukh Krishi Vidyapeeth, Akola and aimed to synthesized silver nano-particles from silver nitrate solution using leaf extracts of Neem, Tulsi, Custard apple and Guava. The reason of using leaf extracts was the biomolecules present in the plants act as reducing and stabilizing agents and increase the rate of reduction of silver metal and synthesis of nano-particles. The characterization and detection of synthesized nano-particles were confirmed using the SPR opticle absoption band peak ranges from 420 to $560 \mathrm{~nm}$ by UV-visible Spectrophotometer and screening of antimicrobial potential against citrus fruit pathogen by disk diffusion method. These biosynthesized silver nano-particles were mixed with guargum as a sticking agent and used as a coating material for Nagpur mandarin to increase the shelf life of mandarin fruits. It was found that green synthesized silver nano-particles increase the shelf life of Nagpur mandarin by arresting weight loss, fruit decay rate and microbial count due to antimicrobial activity of silver nano-particles and leaf extracts without affecting quality of fruits for two months.

\section{Introduction}

Nanotechnology is one of the fast developing frontiers in the field of research and technology. It refers to the branch of science and engineering dedicated to materials, having dimensions in the order of $100^{\text {th }}$ of $\mathrm{nm}$ or less. It is reported that, the nanoparticles act as fundamental building blocks of nanotechnology. The silver nanoparticle shows antibacterial, antiviral and antiinflammatory activity against various pathogens like Alternaria alternate, Penicillium digitatum, Alternaria citri, Botryodiblodia theobromae, Fusarium sp., etc. (El-Sayed et al., 2013). Different plant leaf extracts are used to synthesis of nanoparticles is an important advantage of green synthesis and also used for large scale synthesis of nanoparticles. Ghorbani et al., 2011 reported that the biosynthesis of nanoparticles is ecofriendly and efficient method than rest of two methods i.e. physical and chemical. They also reported that, it is 
eco-friendly, non-toxic as well as easy to implement. Hence, green synthesis of nanoparticles provides excellent advantages such as cost effective, to protect environment, easily prepare large scale synthesis of silver nanoparticles and this method there is no need to energy, temperature and toxic chemicals. In the present study, Azardirachta indica (Kumar et al., 2015), Ocimum sp. (Bindhani and Panigrahi, 2015), Annona squamosa (Singh and Vidyasagar, 2014) and Psidium guajava (Sriram and Pandidurai, 2014) were used for source of reducing agent. The plant is easily available in all the regions in Akola. All these plants extract show various biological effects, such as antibacterial, antifungal, and antioxidant activities.

\section{Materials and Methods}

The experiment will be carried out at Post Harvest Technology, Department of Horticulture, Dr. Panjabrao Deshmukh Krishi Vidyapeeth, Akola. Experiment consisting of synthesis of different green nanoparticles and its coating on Nagpur mandarin fruits for increasing the shelf life of Nagpur mandarin fruits.

\section{Preparation of leaf extract}

Preparation of the leaf extract from Four Indian medicinal plants, Azardirachta indica, Ocimum sp., Annona squamosa and Psidium guajava were selected from Akola, India, on the basis of cost effectiveness, ease of availability and medicinal property.

Fresh leaves will finely cut and washed with distilled water. $20 \mathrm{~g}$ of leaves will be added to $100 \mathrm{ml}$ of distilled water and boiled for 2 minutes in a water bath. After cooling, it will filtered through Whatman Filter paper no. 1 to obtain aqueous extract of definite concentrations (Lalitha et al., 2013). Freshly prepared aqueous extract will be used for synthesis.

\section{Synthesis of silver nano-particles}

For synthesis of silver nano-particles, above prepared plants leaves extract were added to $0.01 \mathrm{mM} \mathrm{AgNO}_{3}$ solution at 1:4 ratio and the mixture stirred continuously for 5-10 minutes using magnetic stirrer with $650 \mathrm{rpm}$. The silver ions were reduced to silver nanoparticles within few minutes by leaves extract. The quick conversion of solution colour showed the formation of silver nanoparticles by observing colour change from greenish yellow to brown colour (Niveadhitha et al., 2015 and Ramteke et al., 2013).

\section{Characterization of synthesized silver nano-particles}

The characterization study of silver nanoparticles was done by the absorption of biosynthesized AgNPs measured by UV-VIS spectroscopy.

Screening of antimicrobial potential of synthesize green silver nano-particles against citrus fruit pathogen

After preparation and characterization of green silver nano-particles different concentration of green nano-particles were prepared and screening of antimicrobial potential of synthesize green silver nanoparticles against citrus fruit pathogen was standardized by disk diffusion method. The green nano-particles were selected for further experiment (Banerjee et al., 2014).

\section{Application of solution with green silver nano-particles on the surface of Nagpur mandarin}

After screening of antimicrobial potential of green silver nano particles against citrus fruit pathogens, the solution of green silver nano particles were prepared with gaur gum (3.33\%) for dipping or coating of Nagpur mandarin fruits (Syed et al., 2015). 


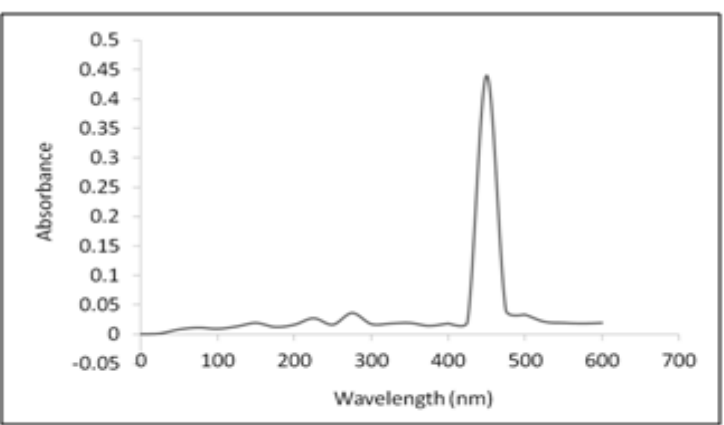

A

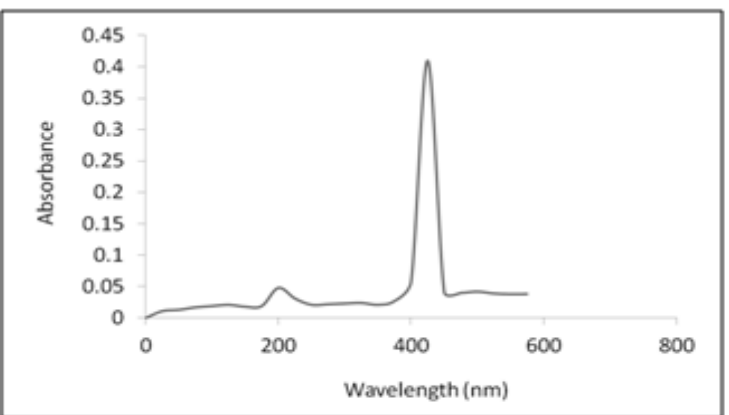

C

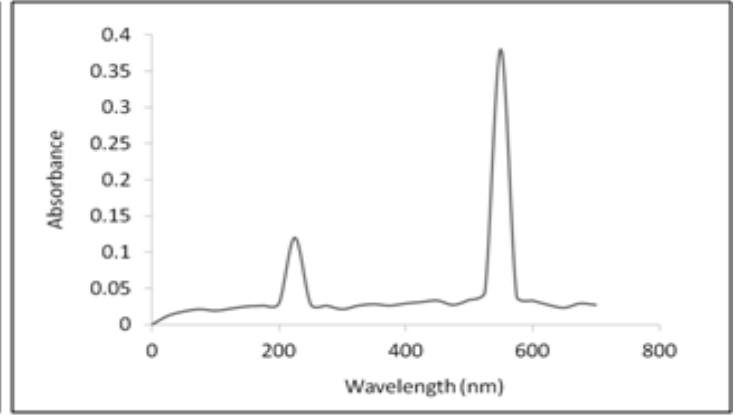

B

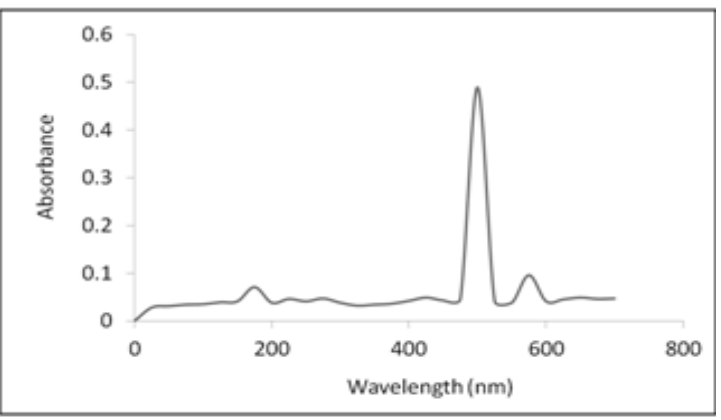

D

Fig.1 UV-vis absorption spectrum of silver nanoparticles. From (A) Tulsi (B) Guava

(C) Neem and (D) Annona leaf extracts

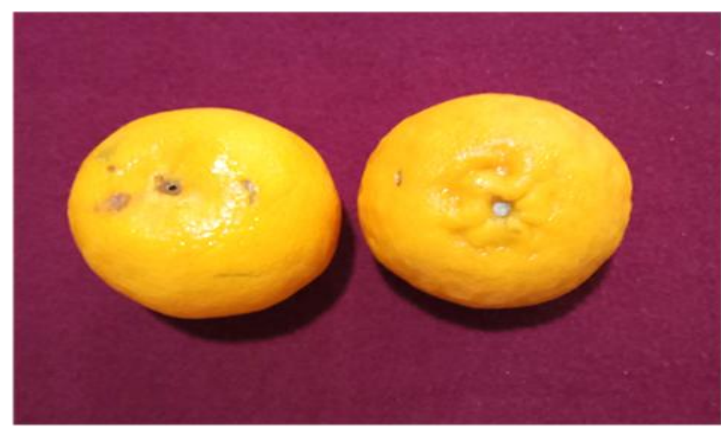

Nagpur mandarin fruits treated with Green SilverNano-particles

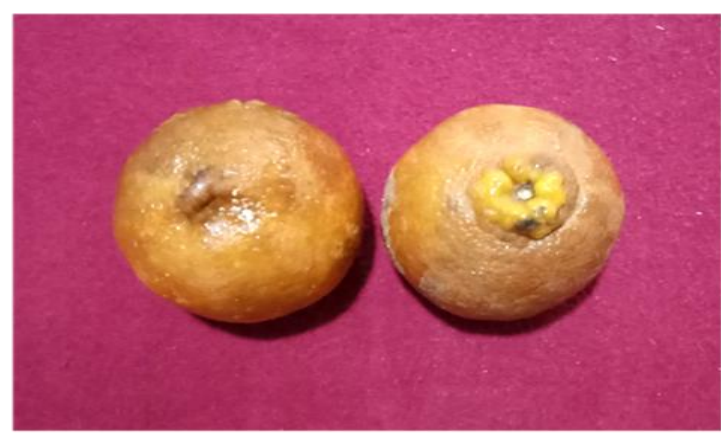

Nagpur mandarin fruits Control condition

Plate.1 Nagpur mandarin fruits after two months of storage

\section{Results and Discussion}

\section{AgNP characterization (UV-VIS analysis)}

Silver nitrate has distinctive properties such as good conductivity, catalytic and chemical stability. Silver nanoparticles (AgNPs) appear yellowish brown in colour in aqueous medium as a result of surface Plasmon vibrations [18]. When the leaf extracts of neem, tulsi, guava and annona were added to aqueous silver nitrate solution, the colour of the solution changed from faint light to yellowish brown to reddish brown and finally to colloidal brown indicating AgNP formation. The UV-VIS spectra recorded after time intervals of $15 \mathrm{~min}, 60 \mathrm{~min}$ and $24 \mathrm{~h}$ from the initiation of reaction. Absorption spectra of AgNPs formed in the reaction media has absorption maxima in the ranges 
from 420 to $560 \mathrm{~nm}$ different for different leaf extract due to surface Plasmon resonance of AgNPs. The UV-visible spectra recorded, implied that most rapid bioreduction was achieved using Ocimum sp. leaf extract as reducing agent followed by Azardirachta indica leaf extracts. Fig. 1 showed the UVvisible absorption spectrum of silver nanoparticles.

\section{Antimicrobial activity}

The antimicrobial activity of these prepared silver nano-particles was tested against citrus pathogens by using disc diffusion method. Green synthesis of Ocimum $s p$. showed very strong inhibitory actions against citrus pathogen followed by Azardirachta indica. The highest zone of inhibition of Ocimum $s p$. (11mm) was found against citrus pathogen followed by Azardirachta indica $(10 \mathrm{~mm})$ and lowest zone of inhibition was found in other green synthesized nano-particles.

\section{Coating of fruits}

The freshly harvested Nagpur mandarin fruits obtained from orchard were initially analyzed for physico-chemical parameters and then the solution of green silver nano particles were prepared with gaur gum $(3.33 \%)$ for dipping or coating to the fruits. Fruits were immersed in the guar gum and nano-particle solution for $3 \mathrm{~min}$. and then these fruits were packed in board cartons with small hole at each of the four sides in cold storage. Both treated and control samples were analyzed for physicochemical parameters at 15 days interval from the day of coating.

The experimental results showed that, the coating of Nagpur mandarin fruits with these nano-particles improve the shelf life of Nagpur mandarin fruits for sixty days due to antimicrobial activity of green synthesized silver nano-particles and barrier provided by coating against respiration and evaporation. From the above study it is concluded that, the green synthesis is the easiest, safe and ecofriendly method of synthesis nanoparticles. These green synthesized nanoparticles with gaur gum solution coated on Nagpur mandarin, it increase the shelf life of fruits without affecting the quality of fruits.

\section{References}

Banerjee Priya, Mantosh Satapathy, Aniruddha Mukhopahayay and Papita Das, 2014. Leaf extract mediated green synthesis of silver nanoparticles from widely available Indian plants: synthesis, characterization, antimicrobial property and toxicity analysis. Bioresources and Bioprocessing, 1:3.

Bindhani and Panigrahi, 2015. Biosynthesis and Characterization of Silver Nanoparticles (SNPs) by using Leaf Extracts of Ocimum Sanctum L (Tulsi) and Study of its Antibacterial Activities. J Nanomed Nanotechnol, pp-2-5.

El-Sayed M. Embaby, M. Hazaa, Laila F. Hagag, Talaat El-Sayed Ibrahim and Faten S. Abd El-Azem, 2013. Decay of some citrus fruit quality caused by fungi. J. of Applied Sci. Res., 9(11): 5920-5929.

Ghorbani H. Reza, A. Akbar Safekordi, H. Attar and S. M. Rezayat Sorkhabadi, 2011. Biological and non-biological methods for silver nanoparticles synthesis. Chem. Biochem. Eng. Q. 25 (3):317-326.

Kumar Sajesh N. K., Prem Jose Vazhacharickal, Jiby John Mathew and Jyothimol Joy, 2015. Synthesis of silver nano particles from neem leaf (Azadirachta indica) extract and its antibacterial activity. CIBTech J. of Biotech., 4 (2):20-31.

Lalitha A., R. Subbaiya and P. Ponmurugan, 
2013. Green synthesis of silver nanoparticles from leaf extract Azhadirachta indica and to study its anti-bacterial and antioxidant property. Int. J. Curr. Microbiol. App. Sci., 2(6): 228-235.

Niveadhitha S., R. Marx Nirmal, K. Sudha and S. Suhashini, 2015. Green synthesis of silver nanoparticles using plant (Azardirachta indica) leaf extract. Food processing tech. Vol. 5(6):477-478.

Ramteke Charusheela, Tapan Chakrabarti, Bijaya Ketan Sarangi, and Ram-Avatar Pandey, 2013. Synthesis of silver nanoparticles from the aqueous extract of leaves of Ocimum sanctum for enhanced antibacterial activity. J. of Chemistry: 1-8.

Singh P. Shivakumar and G. M. Vidyasagar,
2014. Biosynthesis, characterization, and antidermatophytic activity of silver nanoparticles using raam phal plant (Annona reticulata) aqueous leaves extract. Indian J. of Materials Sci.,1-5.

Sriram T. and V. Pandidurai, 2014. Synthesis of silver nanoparticles from leaf extract of Psidium guajava and its antibacterial activity against pathogens. Int. J. Curr. Microbiol. App. Sci., 3(3): 146-152.

Syed Wasim Ahmad Shah, Muhammad Jahangir, Muhammad Qaisar, Sher Aslam Khan,Talat Mahmood, Muhammad Saeed, Abid Farid and Muhammad Liaquat 2015. Storage stability of Kinnow fruit (Citrus reticulata) as affected by CMC and guar gum-based silver nanoparticle coatings. Molecules, 20: 22645-22661.

\section{How to cite this article:}

Deshmukh. S. D., S. R. Patil and Sonkamble. A. M. 2020. Green Synthesis of Silver NanoParticles using Different Plant Leaf Extract for Nagpur Mandarin Coating - An Eco-Friendly Approach. Int.J.Curr.Microbiol.App.Sci. 9(06): 1132-1136. doi: https://doi.org/10.20546/ijcmas.2020.906.140 